\title{
ARTIGO
}

\section{A CONCEPÇÃO DO YOGA SEGUNDO PERIÓDICOS DA EDUCAÇÃO FÍSICA BRASILEIRA}

The design of yoga second journals of the Brasilian physical education

La concepción del yoga conforme revistas brasileñas de educación física

\author{
Ana Paula Góis Jatobá \\ Universidade Federal de Sergipe - Brasil \\ Renato Izidoro da Silva \\ Universidade Federal de Sergipe - Brasil \\ Fabio Zoboli \\ Universidade Federal de Sergipe - Brasil
}

\begin{abstract}
Resumo
O artigo objetivou mapear e analisar a produção do conhecimento acerca do yoga no âmbito das publicações em periódicos da Educação Física brasileira. Metodologicamente, tratou-se de uma pesquisa de revisão de literatura sob o viés qualitativo tendo como amostra textos completos online de 06 periódicos da Educação Física. Como critério de busca foram digitadas as palavras-chaves "yoga" e "ioga" na opção de busca "todos". A análise dos 44 textos encontrados apontou que poucos são os que tratam do yoga com alguma profundidade teórica próprio deste campo. Na maior parte da produção o tema yoga é colocado como uma atividade física sem um maior embasamento teórico na literatura clássica ou específica, retirando-o do seu contexto original, desprovendo o yoga assim de sua essência.
\end{abstract}

Palavras-chave: Yoga. Produção do conhecimento. Periódicos da educação física brasileira.

\begin{abstract}
The article aimed to map and analyze the production of knowledge about yoga in the context of publications in periodicals of physical education brazilian. Methodologically, this was a survey of literature review under the qualitative bias as sample full-text 06 online physical education journals. As search criteria have been entered the keywords "yoga" and "Yoga" in the search option "all". The analysis of the 44 texts found pointed out that there are few that deal with yoga with some theoretical depth of the field itself. Most of the yoga theme production is placed as a physical activity without a greater theoretical basis in classical literature or specific, off from its original context, depriving the yoga way of its essence.
\end{abstract}

Keywords: Yoga. The production of knowledge. Physical education brazilian periodicals. 


\section{Resumen}

El artigo tiene como objetivo mapear y analizar la produción del conocimento acerca del yoga en el ambito de las publicaciones en revistas brasileñas de Educación Física. Metodológicamente, se trata de una investigación de revisión de literatura de carácter cualitativo teniendo como muestra textos completos online de 06 revistas de Educación Física. Como criterio de búsqueda fueron digitadas las palabras-claves "yoga" y "ioga" en la opción de busca "todos". El análisis de los 44 textos encontrados apuntó que pocos son los que tratan del yoga con alguna profundidad teórica propia de este campo. En la mayor parte de la producción el tema yoga es colocado como una actividade física sin un mayor embasamiento teórico en la literatura clásica o específica, retirandolo de su contexto original, despojando el yoga así de su esencia.

Palabras-clave: Yoga. Producción del conocimiento. Revistas brasileñas de Educación Física.

\section{Introdução}

Este artigo tem como objeto o yoga segundo publicações acadêmicas veiculadas em periódicos da Educação Física brasileira. Enquanto objetivo geral, de um ponto de vista histórico e epistemológico, buscamos investigar o panorama da produção do conhecimento por parte de pesquisadores do campo acerca do que vêm sendo abordado sobre o tema yoga na produção acadêmica quanto às suas vertentes teóricas e práticas inseridas e adaptadas em diferentes contextos pedagógicos da Educação Física.

A Educação Física e o yoga estabelecem uma relação do tipo dialética, formam uma unidade institucional, porém uma unidade em que habita dois polos contrários - sendo o yoga um polo e a Educação Física outro. A nosso ver, o fundamento desse encontro contraditório está localizado na oposição lógica acerca da compreensão que cada uma tem sobre o corpo humano. Enquanto o yoga observa e vivencia o corpo por meio de exercícios físicos como uma propedêutica para a prática da meditação hipocinética que promove uma comunicação entre corpo e mente; a Educação Física propõe experiências corporais cujo fim propedêutico é dar condições ao corpo de atingir estágios físicos e fisiológicos mais eficientes.

Dessa forma, lançamos a seguinte hipótese para este estudo: "enquanto o yoga busca tornar o corpo eficiente para a meditação com quase ausência de movimento, a Educação Física objetiva tornar o corpo eficiente para o mesmo atingir performances cada vez mais vigorosas e hipercinéticas". Tais fundamentos particulares de cada área estão possivelmente associados, respectivamente, às suas tradições filosóficas, no caso o hinduísmo e o positivismo. Não obstante, considerando que tais filosofias têm historicamente como fim orientar a organização de suas sociedades, necessário ter em mente que as perspectivas da Educação Física sobre o yoga, segundo as publicações acadêmicas da área, implicam 
dimensões culturais do conhecimento que, consequentemente, tocam em tradições discursivas tanto no campo da oralidade quanto no da escrita (literatura).

Etimologicamente o termo yoga deriva da raiz $Y u j$, que significa ligar, manter unido, unir (ELIADE, 1996). Da própria etimologia do termo se pode extrair o conceito e a essência do yoga, que é promover a consciência de união com o divino; não exatamente de duas partes, mas ser uma unidade: formar um com tudo (o Todo). Esta consciência de união se dá de duas formas: a) de modo mais imediato e próximo da matéria, da união consigo mesmo: e por isso o yoga é uma filosofia de auto-observação e autoconhecimento, na qual, por meio da prática de técnicas e procedimentos, o ser alcança sua mais profunda essência, a unidade (a divindade no homem) (HARIHARANANDA, 2006); b) É também união com o absoluto. Ao exercitar o autoconhecimento em sua plenitude e alcançar sua identificação com o ser, definido por Hariharananda (2006) como a divindade pessoal que nos governa, guia, mantém e preserva; o ser humano também adquire a consciência de sua união com o universo, com o absoluto, com a consciência cósmica (Atmam).

Percebemos que diferente do que se colocou durante muito tempo no Ocidente, o yoga não proporciona a união de partes afastadas, mas sim é um caminho para adquirir a consciência da união sempre existente. O ser humano nunca se separou de Deus, apenas criou ou foi acometido por essa ilusão dicotômica. O yoga é, por isso, uma técnica de ascese e um método de meditação: conjunto de técnicas e ensinamentos práticos que, como dito, objetiva a percepção do "si" no Cosmos. Além de seu aspecto prático o yoga possui também uma estrutura iniciática, isto é, uma propedêutica litúrgica que nos coloca a concreta necessidade de um mestre, uma vez que, como aponta Eliade (1996), não se aprende yoga sozinho, é preciso a orientação de um mestre ou guru.

Assim, o presente artigo pretende compreender como o yoga, apesar de sua origem asiático-oriental, - o que implica discrepâncias culturais e epistemológicas para com a origem euro-ocidental da Educação Física - vem sendo assimilado por essa última segundo sua lógica, métodos, objetivos e princípios historicamente positivistas. Especificamente, objetivamos identificar que tipo de relação a Educação Física vem estabelecendo com o yoga mediante tendências das investigações em termos de temáticas e de aportes teóricometodológicos que foram utilizados; tendo como distinção principal as perspectivas das ciências humanas e sociais, assim como das ciências biológicas e da saúde.

Para tal apresentamos o texto a partir de três partes: num primeiro momento exibimos algumas tensivas epistemológicas no que tange a relação do yoga com a Educação Física, na 
segunda parte dissertamos sobre os procedimentos metodológicos que nortearam nosso estudo para na terceira e última parte do artigo discorrermos sobre os dados coletados.

\section{Ioga e educação física: algumas tensões}

Como base para uma compreensão imediata da proposta deste escrito, é preciso estabelecer como ponto de partida pressupostos de cunho geográfico, histórico e epistemológico. Yoga e Educação Física possuem origens distintas e que, portanto, as relações entre ambas implicam como fundamento um encontro entre modos de pensar, agir e sentir diferentes em relação ao corpo humano e os conhecimentos filosófico-epistemológicos a ele relacionados. Afinal, como nos cita Bártolo (2007), onde se encontra um corpo dever-se-á encontrar também uma rede de relações instrumentais, uma série em funcionamento, de operadores epistêmicos, uma lógica de produção de sentidos, de um determinado sentido legitimador da rede de relações, do funcionamento dos operadores, do próprio procedimento das lógicas produtivas.

Resumidamente, para estabelecer uma definição de partida e introdutória, o yoga pode ser considerado, apesar de suas variações, como um movimento cultural e institucional milenar, que pode ser alinhado, geográfica, histórica e culturalmente, a outras manifestações do Oriente. O yoga nasceu na Índia há aproximadamente 5000 anos, e até hoje grande parte da população indiana adota o yoga como filosofia de vida, que vai muito além de uma metodologia de prática corporal qualquer; consistindo numa disciplina filosófica e ética completa, sem a qual sua pratica carece de direcionamento teórico e metodológico.

O yoga, como sistema filosófico, está descrito nos Vedas, segundo Salmoni (1978, p. 38), é a “[...] mais antiga produção literária dos antigos indianos, conservada nos manuscritos sânscritos [...]", que formam um conjunto de hinos sagrados, em que os brâmanes acreditam terem sido revelados conhecimentos existentes na literatura milenar indiana. Os Vedas comportam “[...] normas civis e religiosas (os preceitos religiosos regulam a vida toda dos hindus) e são dedicados ao Senhor, à alma de todos os Seres, à alma de todos os Deuses, à Veda, ao Conhecimento" (SALMONI, 1978, p. 38). É necessário considerar que os Vedas possuem uma dupla importância: a da forma (da palavra) e a do conteúdo (do conhecimento).

Basicamente, a finalidade do yoga é servir de meio - um conjunto de meios - para se atingir certa noção de consciência pura e suprema. Para tal existem algumas manifestações de yoga, porém apresentamos as 05 maiores e mais conhecidas: 
a) Karma Yoga: yoga da ação, a que entendesse qualquer ação por momento presente livre do interesse dos seus frutos desde que sendo observados os elementos éticos. A ação deve ser executada da melhor forma possível, com atenção no momento presente, consciente e correta, Sem apego aos resultados físicos; realiza-se de forma desinteressada (YOGANANDA, 2009 e 2012). Espera-se com isso desenvolver a paciência, tolerância, estabilidade mental e emocional, sua prática geralmente, envolve os Yamas e Nyamas, e é considerado necessário a todos os outros tipos e sistemas do yoga.

ß) Bhaki Yoga: yoga da devoção, ou, como o monge indiano Swami Vivekananda prefere chamar, o yoga do amor como instinto natural e básico da vida, envolvendo a entrega do coração, a busca espiritual em algo simples e positivo. A devoção torna as práticas de autoconhecimento, concentração e meditação naturais e adoráveis. Trata-se de uma atitude interior e é aplicada de forma combinada com o Karma Yoga e o Jñana Yoga utilizados em outros sistemas de yoga (VIVEKANANDA, 2013).

y) Jñana Yoga: yoga da realização do si mesmo por meio de discernimento do que é real e do que é ilusório. Isso se faz a partir de questionamentos e do conhecimento intelectual adquiridos de forma pessoal, prática, experimental e vivencial. Quando esses recursos racionais são utilizados à exaustão e esgotados, transcende-se suas barreiras, chegando a desenvolver o conhecimento intuitivo, universal e absoluto;

б) Raja Yoga: significa caminho real. Consiste no ramo mais abrangente de todos do yoga. Tal nomenclatura deriva do fato de representar a essência do caminho e da disciplina. Sua prática apresenta oito passos para a realização do yoga descritos nos Sutras, de Patanjali; por isso é também conhecido como Patanjali yoga ou Ashatanga Yoga. Vários ramos do yoga são associados diretamente a este. E outros, mesmo que não derivem diretamente deste, costumam constituir sua práticas com elementos combinados das técnicas e práticas do Raja Yoga. O Kriya yoga, o Kundalini yoga e o Hatha yoga são alguns dos ramos que derivam ou fazem combinação de técnicas com o Raja yoga.

E) Hatha Yoga: caminho da purificação ou do equilíbrio das energias do corpo. Etimologicamente Hatha Yoga significa o yoga do Sol e da Lua. "Há" significa "Sol" e "Tha", "Lua". Ambos simbolizam o equilíbrio de dois polos, respectivamente: masculino e feminino; inspiração e expiração; atividade e passividade (HERMÓGENES, 1993).

Evidenciando alguns detalhes sobre esse último, devido ao seu maior vínculo com a Educação Física no Ocidente, o Hatha yoga surgiu aproximadamente 1300 anos após o Raja yoga. Com grande influencia do tantrismo, deu ao corpo uma importância jamais vista na 
história da filosofia espiritual da Índia. No tantrismo, a teoria de que a santidade só pode ser alcançada em um "corpo divino" é altamente valorizada. O significado do corpo vai além da “fonte de sofrimentos" postulado nas Upanishads. O corpo é agora o instrumento mais seguro e completo que o homem tem à sua disposição para conquistar, paradoxalmente, a morte (alcançar a liberação) (ELIADE, 1996). Ou seja, o que para o Ocidente consiste no fundamento da vida e no símbolo da luta da vida contra a morte; para Hatha yoga, mesmo considerado valorizador do corpo, o valor desse não está para a vida saudável e prolongada, mas sim para uma boa morte e para a liberação, o encerramento de um ciclo indesejado.

Foi devido a esse novo status do corpo dado pelo Hatha Yoga que se inicia um período de interesse e preocupação com as condições físicas deste corpo. Diferentemente dos textos anteriores, agora as escrituras apontam ser necessário que o corpo esteja em perfeitas condições, principalmente para facilitar a meditação e seus fins metafísicos superiores e sutis. No Hatha Yoga se preconiza a vontade de dominar o corpo para transformá-lo em "corpo divino". Porém, Hermógenes (1993) chama a atenção de isso não significar que este novo paradigma, de grande interesse e valorização do corpo, faça do Hatha yoga um ramo materialista do tipo Ocidental. O que ocorre é que aqui o corpo físico não é menos digno de reverências que os corpos sutis.

Outra questão é o fato de que, como ter paz e concentração necessárias para buscar estados meditativos e consequentemente alcançar a divindade ou liberação, em meio aos desconfortos e dores de um corpo fraco e doentio? "Materialismo não é zelar a partir do veículo físico, mas sim cuidar exclusivamente do corpo. O 'pecado' consiste em tornar como fim o que não é mais do que um meio" (HERMOGÊNES, 1993, p.24). A busca pela saúde e resistência do corpo é para que se possa torná-lo um instrumento adequado para a sintonia com os planos mais sutis - metafísicos e reais - do universo e, com isso, ser possível alcançar a liberação. O corpo representa o cosmos e todos os deuses. Não se pode conseguir a liberação senão a partir do corpo totalmente abandonado. Para tanto é importante ter um corpo sadio e forte (ELIADE, 1996).

Essa leitura sobre o papel do corpo no alcance do estado divino se articulou parcialmente, enquanto ramo do yoga, com a visão ocidental sobre o corpo e seu vigor voltado para o trabalho, a produção e o melhoramento material da vida, inclusive no Brasil. Essencialmente, a principal marca distintiva - e incompatível ou mesmo desmesurada - do yoga em face da Educação Física é seu fundamento metafísico ou espiritual, muitas vezes julgado como sendo de cunho religioso ou simplesmente devocional. Percebemos que existe 
uma incomensurabilidade fundamental - talvez instransponível - entre yoga e Educação Física, na medida em que essa última objetiva uma saúde corporal plena e, assim, um modo de evitar doenças físicas, psíquicas e sociais; enquanto que o yoga, "ao lado do budismo, e diferente ainda de [...] práticas primitivas de curas místicas do corpo, tem como meta a dominação espiritual e a libertação do espírito em relação ao corpo" (ELIADE 1972, p. 62).

Em uma só formulação, a nosso ver, o fundamento dessa contradição pode ser expresso na seguinte proposição hipotética: no interior da relação entre yoga e Educação Física provocada por uma assimilação da primeira por essa última encontramos a lógica do yoga compreendendo a atividade corporal - mais especificamente o Hatha Yoga funcionando para um esquecimento do corpo capaz de favorecer a meditação como um método em que a mente se desprende da matéria para transcender em outros estados de energia no sentido de uma longevidade espiritual; enquanto que a Educação Física compreende logicamente o corpo em função de si próprio, de sua saúde fisiológica que deverá agir em favor da produção de novos aparelhos para servir o próprio corpo.

No caso da mente, ela assume o papel de criar técnicas e tecnologias capazes de favorecer a vida do corpo, seu bem-estar físico e biológico, sua duração, seu desenvolvimento rumo à longevidade carnal. Em um só termo, enquanto a Educação Física está preocupada com a vida do corpo, o yoga se preocupa com a sua morte na matéria. Contudo, atualmente, devido a um encontro histórico, cultural e geográfico entre Ocidente e Oriente, ambas formam uma unidade contraditória. Doravante, a Educação Física se liga, a nosso ver, ao yoga, pela via que Bracht (1999, p. 28) identifica como sendo "o debate epistemológico do campo [...] centrado até o momento fortemente na discussão da produção de um conhecimento sobre o corpo/movimento: [...] corpo/movimento e pensamento; corpo/movimento e linguagem; corpo/movimento e sensibilidade [...]”. Por conseguinte, por tratar do corpo e movimento, o yoga é visto pela comunidade da Educação Física como um de seus objetos por direito.

Não faz parte, no entanto, das finalidades do yoga indiano objetivos como o rejuvenescimento, a longevidade, a saúde, a felicidade corporal; tal como muitas vezes é prometido pelo yoga no Ocidente. Mais do que isso, queremos aqui acentuar o quanto o encontro ocidental entre Educação Física e yoga é paradoxal, já que essa tem como fundamento metódico a imobilidade e a suspensão da consciência das coisas mundanas incluindo o corpo (ELIADE, 1952) - enquanto a Educação Física foca, justamente, no movimento e na consciência corporal como meios para se atingir hábitos fisiológicos e comportamentais cotidianos, tanto no nível individual quanto no da sociabilidade. 
No mesmo sentido de demarcar uma acepção de apoio para maiores desdobramentos, a Educação Física; geográfica, histórica e culturalmente alinhada a manifestações do Ocidente, pode ser entendida, suspendendo, para o momento, uma série de contrassensos teórico-metodológicos e políticos, tanto em sentido lato (anacrônico), quanto em sentido estrito (moderno e contemporâneo). Em termos gerais, a Educação Física pode ser considerada como qualquer atividade, exercício ou cuidado que envolve o movimento corporal capaz de educar o corpo, desde a mais tenra idade, desenvolvendo e estabelecendo hábitos, regras comportamentais e condicionamentos fisiológicos ou fisiopedagógicos alinhados a finalidades biológicas e políticas de uma dada sociedade, independentemente de sua localização histórica e geográfica.

Dessas acepções genéricas, que anacronicamente podem ser compreendidas pela definição contemporânea estrita de Educação Física, é interessante destacarmos três, embora existam outras: a aristotélica (HOURDAKIS, 2001), a lockeana (LOVISOLO, 2010; LOCKE, 1994) e a kantiana (KANT, 2001). Já a segunda acepção, de referência epistemologicamente restrita, compreende a Educação Física não mais como um conjunto de princípios e práticas (anacrônicos) relacionados aos cuidados básicos com o corpo e à formação geral do cidadão promovido pelo pedagogo. Em sentido estrito, a Educação Física, na modernidade, a partir do final do século XIX, mas principalmente ao longo do século XX, passa a ser pensada e organizada institucionalmente. Em outras palavras, começa a designar uma disciplina a compor o currículo escolar ao lado de outras disciplinas.

Não abandonando suas raízes generalistas, sua especialização no sistema educacional vai se restringindo à promoção da saúde física e biológica do corpo (ausência de doenças) e à promoção de uma moralidade nacionalista e militarista. Consequentemente, das mãos dos filósofos da política e da educação, vão para as mãos dos médicos e dos militares que aos poucos formam auxiliares ou técnicos para trabalharem diretamente com a população. Por conseguinte, paulatinamente vai se constituindo um corpo de profissionais (técnicos e professores) especializados e capazes de se organizarem e de delimitarem as diferenças e interações em face de outras disciplinas e profissões. Alguns conhecimentos teóricos e práticos (médicos e militares) são selecionados em detrimento de outros, no sentido de definir as melhores técnicas educativas. Formula preocupações e legislações corporativas quanto à formação de futuros professores.

Conforme Bracht (1999), enquanto campo de atuação sócio pedagógica, até a década de 1970, a Educação Física procurou, historicamente, justificar sua importância social se 
apropriando de diversas práticas corporais cuja origem, existência, função, finalidade e valor lhes são histórica e epistemologicamente independentes: jogos, ginástica, lutas, danças, esportes, folclore, entre outros, incluindo mais recentemente o yoga. Bracht (1999) menciona ainda que durante a década de 70 do século passado, a Educação Física, enquanto campo disciplinar institucionalizado dotada de conhecimento teórico e prático, até então amparada nos dizeres de médicos e militares, passou a ter de oferecer respostas à comunidade universitária e científica concernentes ao seu estatuto de cientificidade.

Especializando-se ainda mais, pauta-se na fisiologia, na medicina esportiva, na cinesiologia etc., subáreas crescentes internacionalmente na época. A partir dos anos de 1980, mais especialmente durante a década de 1990, constatou-se, para além das influências derivadas das especialidades médicas, para as quais o corpo nunca deixará de ser apenas biomecânico, o campo assimila influências das ciências sociais e humanas. Por conseguinte, as ações da Educação Física, sejam elas médicas, militares ou pedagógicas, passam a ser estudadas em termos de sua participação política na formação cultural e econômica da sociedade contemporânea, escolarizada e industrializada. Em suma, a Educação Física, tanto em seu sentido lato quanto stricto, não pode ser vista como um tipo de prática corporal específica como a ginástica, o esporte, a dança, o yoga etc..

Por conseguinte, trata-se de um campo institucional que desempenha mais a função de organizar política, jurídica e economicamente uma série de práticas e disciplinas corporais histórica e culturalmente independentes entre si; mas que não deixam de interagir umas com as outras de modo pontual. Devemos lembrar que embora a Educação Física seja uma instituição responsável por organizar um corpo de profissionais (trabalhadores), as práticas corporais que ela abarca em seu repertório de conteúdos, de teorias e de métodos são também instituições, na medida em que existem figuras - pessoas - jurídicas como associações, confederações, federações, clubes, grêmios, ligas, equipes, sindicatos etc. responsáveis por organizar e controlar modalidades específicas como dança, luta, esportes; sendo que no interior dessas encontramos outras especialidades.

Para o momento, essa contextualização, ainda que breve, tem como fim introduzirmos o ponto de partida histórico e epistemológico relativo ao encontro entre Educação Física e yoga. Com efeito, a nosso ver, esse encontro vem se dando na medida em que, enquanto instituição política, jurídica, econômica e científica, cuja função histórica é a de organizar, sistematizar e legitimar certas prática corporais, em detrimento de outras, voltadas para a formação física, biológica e cultural da população, a Educação Física vem buscando 
incorporar o yoga como mais uma modalidade de prática corporal a ser direcionada para os fins políticos, jurídicos, econômicos e científicos do campo, conforme a atual orientação da sociedade Ocidental democrática neoliberal.

Assim como com outras práticas, como a capoeira, a natação, a ginástica etc.; a instituição Educação Física, mediante seu Conselho Federal $\left(\mathrm{CONFEF}^{1}\right)$, mas, também, através de cursos universitários por meio de seus currículos, vem lançando mão de estratégias para submeter o yoga à sua lógica organizacional, chegando a propor que professores e mestres iogues venham a ser formados/fiscalizados por ela; apesar do yoga possuir suas próprias instituições de formação e prática; justamente porque detém histórias e epistemologias próprias. Sempre com uma trajetória institucional e epistemologicamente independente da Educação Física, no Brasil o yoga se tornou popular nas décadas de 1970 e 1980, num momento de repressão social e política por conta do regime militar.

Em meio à tensão, a prática do yoga era a promessa de uma vida equilibrada, harmonizando aspectos físicos, emocionais, mentais e energéticos. Foi a partir desse momento que o yoga passou a se organizar em grupos, associações, cursos, instituições, escolas, eventos etc. (DE ROSE, 2007, p.32), não nos esquecendo de editoras de livros e revistas nacionais e internacionais - exclusivamente especializadas em publicações sobre tema. Com o passar dos anos a prática do yoga despertou o interesse de pessoas das mais diversas classes sociais, credos e idades, se tornando assim uma prática muito popular em nosso país. Hoje, no Brasil, a prática do yoga não ocorre apenas nos espaços especializados em práticas alternativas, mas, nos mais variados ambientes como academias de musculação e ginástica, escolas, espaços culturais, entre outros.

Variados também são os motivos que levam as pessoas buscarem tal prática, que vão desde a busca por uma atividade física para melhorar a força e flexibilidade, o bem-estar e até como tratamento associado para males psíquicos como depressão, síndrome do pânico e estresse. Esse crescente interesse no yoga no âmbito de nossa sociedade reflete em alguns campos do conhecimento, como a Educação Física, mas também a Psicologia e a Medicina, além de outras áreas. A título demonstrativo da atual relevância acadêmica, exploramos a base corrente do CNPQ à procura de grupos de pesquisa interessados pelo tema yoga ${ }^{2}$. Como resultado, encontramos 7 grupos no total, sendo que esses provem das mais diferentes áreas,

\footnotetext{
${ }^{1}$ A Educação Física virou profissão a partir da lei 9696 de 1 de setembro de 1996, e a partir de então foi instituído o CONFEF.

${ }^{2}$ Essa busca foi feita em 18 de agosto de 2015.
} 
como medicina, comunicação, teologia, artes, educação e apenas um grupo da Educação Física, intitulado "Grupo de Estudos e Pesquisa em Yoga", da UNESP campus de Bauru.

A nosso ver, adiantando um aspecto de nossas conclusões, esse quantitativo de grupos, enquanto possível representativo do interesse da Educação Física pelo yoga, expressa um contrassenso tanto em relação ao número de publicações acadêmicas encontradas (conforme veremos mais à frente) quanto acerca do plano discursivo e prático identificado e vivido, em nosso cotidiano, enquanto profissionais da Educação Física e do yoga simultaneamente - caso da autora que assina este texto. Em outras palavras, de um modo geral, mesmo que ainda difuso, os profissionais que trabalham com atividade física voltados à saúde e à educação declaram verem o yoga como uma prática positiva e eficaz para se atingir fins relativos à saúde física e mental. Nesse sentido, mantemos tacitamente essa dimensão cotidiana e empírica das relações entre yoga e Educação Física, para adentrar consciente e sistematicamente no contexto das produções acadêmicas sobre o assunto, julgando que essas são mais representativas que nossa vivência, de modo que possam estabelecer confluências e contradições que merecem ser investigadas em outros momentos.

Não obstante, a fim de dar maior crédito à revisão de literatura em relação ao nosso senso comum construído empiricamente em nosso cotidiano, vale refletirmos sobre as vantagens e os limites - e, portanto, sua relevância científica - de um estudo bibliográfico em termos de produção de evidências. Por conseguinte, este artigo está alinhado ao que se costuma posicionar, cronologicamente, em relação à década de 1980 e ao "movimento renovador" do campo, (CAPARROZ; BRACHT, 2007) segundo suas possibilidades de se pensar a Educação Física como disciplina acadêmica que produz seus próprios conhecimentos teóricos e metodológicos, relativizando, assim, seu colonialismo epistemológico (GAMBOA, 1995) em relação às ciências-mãe, como a Biologia, a Biomecânica, a Psicologia etc.. Uma revisão de literatura permite construirmos uma consciência epistemológica acerca de nossas dependências, independências, possibilidades e limites na produção de conhecimentos técnicos e tecnológicos; bem como políticos e pedagógicos.

\section{Metodologia}

A prática de mapear e avaliar a produção de conhecimento no campo da Educação Física está aos poucos se tornando recorrente e relevante, ao mesmo tempo em que se configura mais claramente como um campo acadêmico. Vale frisar que a produção do 
conhecimento de uma determinada área é uma característica de campos acadêmicos consolidados, mas extremamente necessária às que estão em consolidação, como é o caso da Educação Física. O objetivo perseguido nesses estudos é, normalmente, identificar possíveis tendências das investigações em termos de temáticas e de contribuições teóricometodológicos que foram utilizadas pela Educação Física, tanto no pensar-fazer científicoacadêmico, quanto no pedagógico. Sobre sua dimensão técnica e instrumental, a presente pesquisa pode ser considerada como integralmente bibliográfica, mais especificamente uma revisão de literatura aplicada predominantemente a periódicos, mas sem perder de vista o contato contingencial com livros, dissertações de mestrado e teses de doutorado.

Os periódicos nos ofereceram textos representativos específicos do universo empírico - ou aplicado - do yoga no campo acadêmico e profissional da Educação Física. Com isso, tomamos consciência de que a revisão de literatura consiste em uma "[...] atividade [que] também permite a inserção do problema em certa área do conhecimento; [com isso] a consulta à literatura cumpre a finalidade de orientar a justificativa da relevância científica do empreendimento [para uma dada área: filosófica, científica e/ou profissional]" (MOROZ; GIANFALDONI, 2006, p. 30). Verificar a contribuição precisa para com uma área acadêmica significa tomar conhecimento, por exemplo, da “[...] inexistência de investigações anteriores sobre o problema, a existência de dados contraditórios em diferentes pesquisas [...], ou mesmo a insatisfação de estudiosos em relação às explicações existentes para o fenômenos". Lembrando que para o nosso estudo, a insatisfação orientadora está atrelada aos modos como a Educação Física vem - acadêmica e profissionalmente - assimilando o yoga enquanto uma de suas práticas pedagógicas ou fisiológicas voltadas para a educação e para a saúde.

A base empírica do objeto estudado consiste nas publicações completas de seis periódicos da Educação Física brasileira. As revistas analisadas foram as avaliadas pelo Qualis periódicos da $\mathrm{CAPES}^{3}$ com o conceito A (A1 e A2) e B (B1 e B2). Para fins de organização da pesquisa, elaboramos uma busca particular em cada site dos periódicos. Os 6 periódicos utilizados para a coleta de dados foram: Revista Motriz (1995-2014); Revista Pensar a Prática (1998-2014); Revista Brasileira de Ciências do Esporte - RBCE (20012014); Revista de Educação Física e Esporte da USP - RBEFE (2004-2014); Revista de Educação Física da UEM (1996-2014); Revista Movimento (1994-2014).

O conteúdo que fora levantado, analisado e interpretado dos referido periódicos estão integralmente disponível na WEB em seus respectivos bancos de dados localizados nos seus

\footnotetext{
${ }^{3}$ Este parâmetro é do período de 07 de fevereiro de 2015 - época em que foi iniciada a pesquisa.
} 
sites. Importante informar que nesses mesmos sítios virtuais é possível encontrar dados relativos à história das revistas, bem como suas políticas editoriais acerca da periodicidade e dos temas de preferência de acordo com suas seções. A figura do periódico acadêmicocientífico é aqui apreendida como fonte empírica exclusiva de nosso objeto de pesquisa, considerando que a produção científica periódica pode ser nacionalmente representativa das abordagens sobre nosso objeto. Isso não significa desconsiderar, para estudos posteriores, a possibilidade de ampliação das fontes para outros meios de publicação como livros, anais, teses, dissertações, cartilhas, leis; além de outros periódicos do campo.

Como critério de busca dos textos nos seis periódicos foram digitadas as palavraschaves "yoga" e "ioga" na opção de ferramenta busca "todos". Localizadas publicações que abordam a temática, criamos um quadro categorial, com a finalidade de organizar nossas análises e discussões. Como critério de corte eliminamos de nossa amostra os resumos publicados em anais de evento. É comum algumas revistas da área publicar um suplemento na revista contendo anais de algum evento. $\mathrm{O}$ quadro que fizemos teve a função de estabelecer uma organização ilustrativa acerca das categorias designadas distribuídas em cinco colunas: $1^{\mathrm{a}}$ coluna [ano; edição]; $2^{\mathrm{a}}$ coluna [título; resumo]; $3^{\mathrm{a}}$ coluna [grande área; área; teoria]; $4^{\mathrm{a}}$

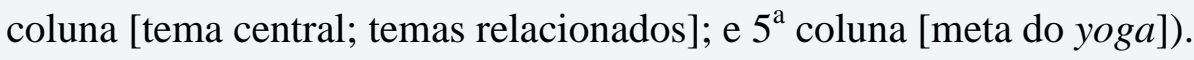

No que concerne às categorias teóricas eleitas no quadro, vale ressaltar que as mesmas possuem a função de fundamentar e objetivar os assuntos/conteúdos que se mostraram mais importantes à pesquisa, cuja finalidade posterior fora a de construir uma discussão entre os autores que estudam a temática. Vale também ressaltar que muitas das publicações investigadas não propõem como tema central questões relativas ao yoga, fazendo desse sempre um tema periférico ou complementar do trabalho. No entanto, esses temas são expressamente abordados de maneira transversal.

\section{Interpretação dos dados}

Como resultado empírico de nossa pesquisa foram encontrados um total de 44 artigos: Revista Motriz (33 publicações); Revista Pensar a Prática (3 publicações); Revista Brasileira de Ciências do Esporte (nenhuma publicação); Revista Brasileira de Educação Física e Esportes da USP - REFEF (6 publicações); Revista de Educação Física da UEM (nenhuma publicação); e, Revista Movimento (2 publicações). Na tabela abaixo apresentamos ano, título, autor(es) e revista dos referidos textos, ordenados cronologicamente: 


\begin{tabular}{|c|c|c|c|}
\hline ANO & TÍTULO & $\operatorname{AUTOR}(\mathbf{E S})$ & REVISTA \\
\hline 1995 & Uma revolução do lúdico e a qualidade de vida. & LORENZETTO, L.A. & MOTRIZ \\
\hline 1997 & $\begin{array}{l}\text { Perspectivas Ecológicas da Educação Corporal- } \\
\text { rumo a qualidade de vida. }\end{array}$ & RIBEIRO, I. C. & MOTRIZ \\
\hline 1998 & $\begin{array}{l}\text { Formação profissional em Educação Física: a } \\
\text { relação teoria e prática. }\end{array}$ & GHILARDI, R. & MOTRIZ \\
\hline 1999 & As iogas como cultura alternativa. & BARROSO, M.M. & MOTRIZ \\
\hline 1999 & $\begin{array}{l}\text { "O divertimento e a dor". Como é possível curar } \\
\text { o corpo recuperando o espírito, na nova era? }\end{array}$ & AMARAL, L. & MOTRIZ \\
\hline 1999 & $\begin{array}{l}\text { A expressividade na dança: visão do } \\
\text { profissional. }\end{array}$ & $\begin{array}{c}\text { SILVA, M.G.S; } \\
\text { SCHWARTZ, G.M. }\end{array}$ & MOTRIZ \\
\hline 1999 & $\begin{array}{l}\text { Corpo civilizado, corpo reencarnado: o moderno } \\
\text { e o alternativo nas representações do corpo. }\end{array}$ & $\begin{array}{l}\text { ALBUQUERQUE, } \\
\text { L.M.B. }\end{array}$ & MOTRIZ \\
\hline 1999 & $\begin{array}{l}\text { Atitude de trabalhadores quanto a prática de } \\
\text { atividade física no tempo livre. }\end{array}$ & DEUTSCH; S. & MOTRIZ \\
\hline 1999 & $\begin{array}{l}\text { Valorização da Educação Física: da produção } \\
\text { acadêmica ao reconhecimento individual e } \\
\text { social. }\end{array}$ & $\begin{array}{l}\text { MACEDO, R.L; } \\
\text { ANTUNES, R.C.F.S. }\end{array}$ & $\begin{array}{l}\text { PENSAR A } \\
\text { PRÁTICA }\end{array}$ \\
\hline 1999 & $\begin{array}{l}\text { A Educação Física e as práticas corporais } \\
\text { alternativas: A produção científica do curso de } \\
\text { graduação em Educação Física da UNESP- Rio } \\
\text { Claro de } 1987 \text { à } 1997 .\end{array}$ & MATTHIESEM, S. Q. & MOTRIZ \\
\hline 2000 & $\begin{array}{l}\text { Análise dos Efeitos Quantitativos e Qualitativos } \\
\text { de um Programa de Educação Física sobre a } \\
\text { Flexibilidade do Quadril em Indivíduos Com } \\
\text { Mais de } 60 \text { Anos. }\end{array}$ & $\begin{array}{l}\text { UENO, L.M; OKUMA, } \\
\text { S.S; MIRANDA, M.L; } \\
\text { JACOB FILHO, W; } \\
\text { HO, L.L. }\end{array}$ & MOTRIZ \\
\hline 2002 & $\begin{array}{l}\text { Da educação física escolar: intelecto, emoção e } \\
\text { corpo. }\end{array}$ & LOVISOLO, H. & MOTRIZ \\
\hline 2004 & $\begin{array}{l}\text { Energia: a moeda corrente da cultura corporal } \\
\text { alternativa. }\end{array}$ & $\begin{array}{l}\text { SIVIERO, E.K; } \\
\text { LORENZETTO, L.A. }\end{array}$ & MOTRIZ \\
\hline 2004 & $\begin{array}{l}\text { Práticas Corporais alternativas: formação em } \\
\text { Educação Física. }\end{array}$ & $\begin{array}{l}\text { COLDEBELLA, A.O.C; } \\
\text { LORENZETTO, L.A; } \\
\text { COLDEBELLA, A. }\end{array}$ & MOTRIZ \\
\hline 2005 & $\begin{array}{l}\text { Significados da ginástica para mulheres } \\
\text { praticantes em academia. }\end{array}$ & FERNANDES, R.C. & MOTRIZ \\
\hline 2005 & $\begin{array}{l}\text { Estudo comparativo entre a flexibilidade } \\
\text { articular de praticantes de yoga e de outras } \\
\text { atividades físicas. }\end{array}$ & $\begin{array}{l}\text { SILVA, M; REBELO, } \\
\text { H.T. }\end{array}$ & MOTRIZ \\
\hline 2006 & $\begin{array}{l}\text { Qualidade de vida, terceira idade e atividades } \\
\text { físicas. }\end{array}$ & $\begin{array}{l}\text { PASCOAL, M; } \\
\text { SANTOS, D.S.A; } \\
\text { BROEK, V.V.D. }\end{array}$ & MOTRIZ \\
\hline 2007 & $\begin{array}{l}\text { A capoeira do Mercado Modelo de Salvador: } \\
\text { gestualidades performáticas de corpos em } \\
\text { exibição. }\end{array}$ & $\begin{array}{l}\text { FARIAS, R.C; } \\
\text { GOELNER, S.V. }\end{array}$ & REBEF \\
\hline 2008 & $\begin{array}{l}\text { Educação física e práticas corporais alternativas: } \\
\text { o trabalho com o corpo em questão. }\end{array}$ & $\begin{array}{l}\text { CEZANA, J; SOUZA } \\
\text { NETO, S. }\end{array}$ & MOTRIZ \\
\hline 2008 & $\begin{array}{l}\text { O despertar da consciência corporal: um desafio } \\
\text { para o futuro profissional de Educação Física. }\end{array}$ & ALVES, F.S. & MOTRIZ \\
\hline 2008 & $\begin{array}{l}\text { Educação Física, ser professor e profissão } \\
\text { docente em questão. }\end{array}$ & $\begin{array}{c}\text { FIGUEIREDO, Z.C; } \\
\text { SILVA, E.M; } \\
\text { ANDRADE FILHO, N.F; } \\
\text { LOYOLA; R.C; } \\
\text { MARQUES, F.B; } \\
\text { OLIVEIRA, R.G; } \\
\text { ARAÚJO, M.S; } \\
\text { ALMEIDA, S.G; } \\
\text { BUFON, V.M. }\end{array}$ & $\begin{array}{l}\text { PENSAR A } \\
\text { PRÁTICA }\end{array}$ \\
\hline 2009 & $\begin{array}{l}\text { Fisiomotricidade em dor, autonomia funcional e } \\
\text { massa óssea de idosas osteoporóticas. }\end{array}$ & $\begin{array}{l}\text { CASTRO, K.V.B; } \\
\text { SILVA, A.L.S; LIMA, }\end{array}$ & MOTRIZ \\
\hline
\end{tabular}




\begin{tabular}{|c|c|c|c|}
\hline & & $\begin{array}{l}\text { J.M.M; NUNES, W.J; } \\
\text { CALOMENI, M.R; } \\
\text { SILVA, V.F. }\end{array}$ & \\
\hline 2009 & $\begin{array}{l}\text { Ecomotricidade: sinergia entre educação } \\
\text { ambiental, motricidade humana e pedagogia } \\
\text { dialógica. }\end{array}$ & $\begin{array}{l}\text { RODRIGUES, C; } \\
\text { GONÇALVES JUNIOR, } \\
\text { L. }\end{array}$ & MOTRIZ \\
\hline 2009 & $\begin{array}{l}\text { A palavra é gesto: reflexões estéticas sobre o } \\
\text { corpo. }\end{array}$ & $\begin{array}{l}\text { NÓBREGA, T.P; } \\
\text { MEDEIROS, R.M. }\end{array}$ & MOTRIZ \\
\hline 2009 & $\begin{array}{l}\text { Prácticas corporales. Traducción de sentidos em } \\
\text { la ciudad. }\end{array}$ & CACHORRO, G.A. & $\begin{array}{l}\text { PENSAR A } \\
\text { PRÁTICA }\end{array}$ \\
\hline 2009 & $\begin{array}{l}\text { Os conteúdos escolares das disciplinas de } \\
\text { história e ciências e suas relações com a } \\
\text { organização curricular da Educação Física na } \\
\text { escola. }\end{array}$ & $\begin{array}{l}\text { ROSÁRIO, L.F.R; } \\
\text { DARIDO, S.C. }\end{array}$ & REBEF \\
\hline 2009 & $\begin{array}{l}\text { Estilo de vida: lazer e atividades lúdico- } \\
\text { desportivas de escolares de Santa Cruz do Sul. }\end{array}$ & BURGOS, M.S. & REBEF \\
\hline 2009 & $\begin{array}{l}\text { A inserção da regulamentação da profissão na } \\
\text { área de Educação Física, dez anos depois: } \\
\text { embates, debates e perspectivas. }\end{array}$ & $\begin{array}{l}\text { ALMEIDA, M.B; } \\
\text { MONTAGNER, P.C; } \\
\text { GUTIERREZ, G.L. }\end{array}$ & MOVIMENTO \\
\hline 2010 & $\begin{array}{l}\text { O Significado para idosos da prática de } \\
\text { atividades físicas nas praias do litoral alagoano. }\end{array}$ & $\begin{array}{l}\text { GONÇALVES, C.O; } \\
\text { MARCELINO, V.R; } \\
\text { TAVARES, M.C.G.C.F. }\end{array}$ & MOVIMENTO \\
\hline 2010 & $\begin{array}{l}\text { Influência da música preferida e não preferida } \\
\text { no estado de ânimo e no desempenho de } \\
\text { exercícios realizados na intensidade vigorosa. }\end{array}$ & $\begin{array}{l}\text { NAKAMURA, P.M; } \\
\text { DEUSTCH, S; } \\
\text { KOKUBUN, E. }\end{array}$ & REBEF \\
\hline 2010 & $\begin{array}{l}\text { Os níveis de estresse pré-competitivo de atletas } \\
\text { classificados segundo a tipologia dos esquemas } \\
\text { de gênero. }\end{array}$ & $\begin{array}{l}\text { MARQUES, R.S; } \\
\text { CIPRIANI, M; MELO, } \\
\text { G.F; GIAVONI, A. }\end{array}$ & MOTRIZ \\
\hline 2010 & $\begin{array}{l}\text { Universidade, profissão Educação Física e o } \\
\text { mercado de trabalho. }\end{array}$ & PRONI, M.W. & MOTRIZ \\
\hline 2011 & $\begin{array}{l}\text { Repensando a história do Karate contada no } \\
\text { Brasil. }\end{array}$ & FROSI, T.O; MAZO, J.Z. & REBEF \\
\hline 2011 & $\begin{array}{l}\text { O corpo, o desenvolvimento humano e as } \\
\text { tecnologias. }\end{array}$ & $\begin{array}{l}\text { MACHADO, A.A; } \\
\text { ZANETTI, M.C; } \\
\text { MOIOLI, A. }\end{array}$ & MOTRIZ \\
\hline 2011 & $\begin{array}{l}\text { Qualidade de vida em mulheres praticantes de } \\
\text { Hatha Ioga. }\end{array}$ & $\begin{array}{c}\text { COELHO, C.M; LESSA, } \\
\text { T.T; CARVALHO, R.M; } \\
\text { COELHO, L.A.M.C; } \\
\text { SCARI, R.S; } \\
\text { FERNANDES, N.S; } \\
\text { NOVO JUNIOR, J.M. }\end{array}$ & MOTRIZ \\
\hline 2011 & $\begin{array}{l}\text { Mulheres e esporte de risco: um mergulho no } \\
\text { universo das apneístas. }\end{array}$ & & MOTRIZ \\
\hline 2011 & $\begin{array}{l}\text { Conhecimento sobre atividade física dos } \\
\text { estudantes de uma cidade do sul do Brasil. }\end{array}$ & $\begin{array}{l}\text { SILVEIRA, E.F; SILVA, } \\
\text { M.C. }\end{array}$ & MOTRIZ \\
\hline 2011 & $\begin{array}{l}\text { Aptidão funcional de mulheres idosas de } 80 \\
\text { anos ou mais. }\end{array}$ & $\begin{array}{l}\text { HOEFELMANN, C.P.; } \\
\text { BENEDETTI, T.R.B; } \\
\text { ANTES, D.L; LOPES, } \\
\text { M.A; MAZO, G.Z; } \\
\text { KORN, S. }\end{array}$ & MOTRIZ \\
\hline 2012 & $\begin{array}{l}\text { Rompendo fronteiras na Educação Física através } \\
\text { dos videogames com interação corporal. }\end{array}$ & FRAGA, A.F; FINCO, D. & MOTRIZ \\
\hline 2012 & Atitude crítica de idosos sobre atividade física. & $\begin{array}{l}\text { OKIMURA-KERR, T; } \\
\text { OKUMA, S.S. }\end{array}$ & REBEF \\
\hline 2013 & $\begin{array}{l}\text { Adventurous activities, embodiment and nature: } \\
\text { Spiritual, sensual and sustainable? Embodying } \\
\text { environmental justice. }\end{array}$ & HUMBERSTONE, B. & MOTRIZ \\
\hline 2013 & Experiência de treinamento com Nintendo Wii & SPOSITO, L.A.C; & MOTRIZ \\
\hline
\end{tabular}




\begin{tabular}{c|l|c|c}
\hline \multirow{2}{*}{} & $\begin{array}{l}\text { sobre a funcionalidade, equilíbrio e qualidade de } \\
\text { vida de idosas. }\end{array}$ & $\begin{array}{c}\text { PORTELA; E.R; } \\
\text { BUENO, E.F.P; } \\
\text { CARVALHO, W.R.G; } \\
\text { SILVA, F.F; SOUZA, } \\
\text { R.A. }\end{array}$ \\
\hline \multirow{2}{*}{2013} & $\begin{array}{l}\text { The role of exercise for fall prevention in older } \\
\text { age. }\end{array}$ & $\begin{array}{c}\text { TIEDERMANN, A; } \\
\text { SHERRINGTON, C; } \\
\text { LORD, S.R. }\end{array}$ \\
\hline \multirow{2}{*}{2014} & $\begin{array}{l}\text { Validity of body image scales for Brazilian older } \\
\text { adults. }\end{array}$ & $\begin{array}{c}\text { FERREIRA, C; NEVES, } \\
\text { A.N; TAVARES, } \\
\text { M.C.G.C.F. }\end{array}$ & MOTRIZ \\
\hline
\end{tabular}

Tabela 1: Ano, título, autor(es) e revista dos textos sobre a temática do Yoga

Das 5 colunas de nosso quadro de organização e análise categorial dos dados percebemos que as 2 primeiras são mais de cunho técnico $\left(1^{\mathrm{a}}\right.$ coluna [ano; edição]; $2^{\mathrm{a}}$ coluna [título; resumo]) enquanto que as três últimas são de cunho teórico ( $3^{\mathrm{a}}$ coluna [grande área; área; teoria]; $4^{\mathrm{a}}$ coluna [tema central; temas relacionados]; e, $5^{\mathrm{a}}$ coluna [meta do yoga]).

Sobre os dados técnicos ainda vale ressaltar a frequência por ano dos textos pesquisados. Quanto aos anos que apresentaram maior ou menor número de publicações, podemos notar o seguinte resultado: nenhuma publicação (anos de 1996 e 2001); 1 publicação (anos de 1995, 1997, 1998, 2002, 2003, 2006 e 2014); 2 publicações (2004, 2005, 2007 e 2012); com 4 publicações (2008, 2010 e 2013); com 7 publicações o ano de 1999; com 8 publicações o ano de 2011 e o maior quantitativo de publicações apareceu no ano de 2009 com 9 publicações ligadas ao tema yoga.

Para o momento optamos por deixar a análise dos dados técnicos e suas correlações para um nível de conhecimento tácito, ou seja, deixaremos a interpretação desses dados a mercê da subjetividade do leitor. As informações técnicas, embora importantes, tais como o periódico onde o texto foi veiculado e o ano de publicação e seus possíveis cruzamentos com os dados sobre o problema, poderão ser mais bem interpretados em trabalhos posteriores. Dessa forma, a tarefa agora consiste na busca por semelhanças entre os conteúdos de cada um dos trabalhos analisados (categorias teóricas de nossa pesquisa - colunas 3, 4 e 5).

A partir de uma leitura seletiva de semelhanças e diferenças temáticas, além do quantitativo de informações técnicas, alcançamos o elemento mais geral de nosso objetivo de pesquisa: destacar o perfil das publicações sobre yoga relacionadas ao tema da Educação Física e aos seus diferentes subtemas ou temas transversais.

Nota-se pelos resultados empíricos encontrados que o interesse pelo tema do yoga na Educação Física apresenta uma escassez significativa, o que implica elaborar a noção de que apesar de o discurso cotidiano corrente exaltar a importância dessa relação, na prática as ações sistemáticas são ínfimas. Entretanto, em meio a essa carência de publicações nas principais 
revistas da área, um dos periódicos, a Revista Motriz, se destaca de modo impactante, levando-nos inevitavelmente a questionarmos os motivos que a distancia quantitativamente em relação aos demais; sendo que as duas revistas que mais publicaram apresentam três e seis trabalhos cada uma - total de 9 - em face de suas trinta e três veiculações sobre o tema na Motriz. Esse número indica um interesse sistemático no tema do yoga na Educação Física, podendo também indicar a existência de algum problema que necessita de soluções teóricas e/ou metodológicas.

Articulando esses dados numéricos simples a outros conhecimentos técnicos derivados de nossa amostra bibliográfica, vale precisar que, com exceção da Revista Motriz, que declaradamente volta sua política editorial para o campo da Educação Física e Saúde (com maior número de remissões ao tema yoga), todos os periódicos estão orientados editorialmente pela grande área das Ciência Humanas, sendo que a RBEFE (segunda maior ocorrência sobre yoga com seis publicações) e a Revista da UEM (sem ocorrência sobre o tema) apresentam um perfil misto com as Ciências da Saúde. Pautados nessa correlação quantitativa, torna-se possível inferir de antemão que os temas centrais e periféricos mais frequentes implicam de algum modo temas correlatos à saúde. Não obstante, quanto aos temas e subtemas menos frequentes, apenas a leitura empírica forneceu dados consistentes; apesar das intensas dificuldades em identificar objetividade por parte dos autores ao tratarem do yoga; levando à dificuldades no plano da inferência.

Os benefícios de saúde produzidos no corpo físico pela prática do yoga, apesar de não ser essa sua finalidade, é evidenciado pelo olhar da Educação Física. Por exemplo, segundo o Hatha Yoga, Ida e Pingala controlam, no nível físico-corporal, as reações dos sistemas nervosos simpático e parassimpático. Da mesma forma, cada chakra está ligado a um sistema fisiológico, sentido, hormônios e glândulas (TINOCO, 2005). As técnicas do yoga operam diretamente nessas estruturas, harmonizando e equilibrando, consequentemente melhorando a saúde geral do ser. Hariharananda (2006, p. 185) explica a relação entre a prática do yoga e a melhora da saúde física da seguinte forma:

Pela prática da técnica cientifica de Kriya Yoga, todo organismo humano é magnetizado e energizado num curto espaço de tempo. Todos os órgão internos como fígado, pâncreas, baço, glândulas tireoide, pituitária e pineal, responsáveis pela secreção de hormônios e enzimas necessários a saúde do corpo, são ativados. O sangue circulará ativamente no cérebro e na medula suprindo o oxigênio necessário e de forma equilibrada e distribuindo-o por todas as regiões periféricas do corpo. Os sistemas digestivo, gastrintestinal, cardiovascular, respiratório, excretor, nervoso e genital tornam-se ativos e eficientes. 
Fica claro que a perspectiva tradicional do yoga não perde de vista as beneficies físicocorporais produzidas pela técnica realizada em series de exercícios desenvolvidos ao longo da história; contudo, não passa de uma propedêutica visando à iniciação do discípulo. Inúmeros sábios, desde o Rig-Veda ao Yogasutra, contribuíram na formação das técnicas que atualmente fazem parte da disciplina Yoga. Essas técnicas foram agrupadas e catalogadas com o passar dos séculos de acordo com abordagens distintas. As técnicas do yoga estão assim classificadas:

Ásanas: posições físicas elaboradas para proporcionar alongamento muscular, flexibilidade articular e força. Atuam sobre as energias sutis do organismo, desenvolvem a consciência corporal, autocontrole, autopercepção e tem a finalidade de preparar o praticante para as técnicas mais introspectivas. O ásana age no corpo físico e, alem deste, tem influencia direta também nas esferas emocional e mental. A prática do ásana promove uma melhor circulação do prana, revitalizando os sistemas densos e sutis (DE ROSE, 2007).

Pránáyáma: exercícios respiratórios e tem a intenção de ampliar a circulação do prana (energia vital). São exercícios que proporcionam o controle da respiração no sentido de trazer a capacidade da sua plena utilização consciente. Proporciona a percepção completa e o controle voluntário da respiração, fazendo com que esta retorne a um padrão de tranquilidade. Além desses benefícios diretos, as práticas das técnicas de Pránáyámas fazem fluir plenamente o prana à mente. Esta também entra em um estado de calma e o praticante pode ser conduzidos a estados meditativos. Esta relação entre a fluência do prana e a estados mentais agradáveis está descrito num verso do Hathayoga Pradipíká: "Quando o prana flutua, a mente também flutua; quando o prana se torna estável, também a mente se torna estável"(ELIADE,1996, p 193). Dessa maneira, os Pranayanas são uma das principais técnicas do yoga e é, como aponta De Rose (2007), o elo entre as técnicas densas (ásanas) e as sutis (técnicas que trabalham os aspectos energéticos ).

Bandhas: exercícios de contrações musculares que promovem compressões em regiões internas, glandes, plexos e fechos de circulação de energia. Eles podem ser executados em combinação com ásanas e pranayamas ou cada uma individualmente;

Mantra: exercícios vocais, que são executados como cânticos, ou na forma de repetições de determinadas sílabas ou sons. Os mantras promovem uma ativação de percepções internas e levam o praticante a um estado de interiorização, concentração e à meditação respectivamente; 
Mudrá: etimologicamente Mudrá significa: “Atitude que transmite satisfação ou encontro". Na prática, são gestos e posições do corpo que reforçam estados internos, e visam aprofundar estado de concentração e percepção. Os Mudrás são executados em combinação ou após as técnicas de ásanas e pranayamas.

Kriyas: atividade e denomina certas combinações de Mudrás, Bandhas, Pranayamas e mentalizações. Produzem efeitos sobre as energias circulantes no corpo e nos estados meditativos. Algumas combinações específicas que compõem os Kriyas são utilizados na metodologia do Kriya Yoga, o qual trataremos adiante no tópico tipos de yoga.

Yoganidra: técnica recente, se comparada com as demais milenares, foi criada pelo Swami Satyananda na década de 1930. Essa técnica tem por objetivo que o praticante chegue a um estado de relaxamento intermediário entre o sono e a vigília. Durante a prática a mente precisa estar consciente, porém, em um estado de abstração dos sentidos (Pratyahara). Proporciona um profundo relaxamento corporal, aumentando a capacidade de descontração, redução do estresse. Indo além, promove o controle corporal, a distribuição do prana nas correntes vitais; a abstração parcial dos sentidos. Esta técnica pode ser combinada com técnicas de visualização e meditação;

Samyama: compreende três técnicas que são executadas conjuntamente:

a) Dharana: técnica para atingir um determinado estado de concentração, percepção e concepção da alma (HARIHARANANDA, 2006).

b) Dhyana: técnicas de meditação que levam o praticante ao estágio sem forma, no qual não existe mente, intelecto, ego ou pensamento.

c) Samádhi: estado de iluminação interior, a fusão com a alma (Purusa). Os estados meditativos produzem benefícios à saúde. Embora não seja este o objetivo final da prática, eles produzem redução do estresse, equilibra a pressão sanguínea, produz uma energia relaxante, diminui o efeito do susto em situações inusitadas (DE ROSE, 2007).

Yamas e Nyamas: preceitos morais que guiam a conduta do praticante de yoga. Devem ser observados na sua vida cotidiana. Aparecem, embora com outra nomenclatura, em textos antigos como nas Upanishads, no Ramayana e no Mahábhárata (HARIHARANANDA, 2006; DE ROSE, 2007). É função dos yamas e niyamas guiar o praticante no caminho da iluminação e liberação, uma vez que este caminho exige conhecimento e entrega de corpo, mente, emoção e espírito.

Dando sequência a nossa análise, concernente à classe categorial teórica destacamos de maneira principal as teorias e as disciplinas acadêmicas que mais (ou menos) vezes 
abarcaram a relação entre yoga e Educação Física, bem como os temas centrais e periféricos gerais e particulares. Esse tipo de exposição nos permitiu uma compreensão histórica e epistemológica das publicações. Diante disso, foi possível notar, de acordo com uma análise e organização dos conteúdos contidos em títulos e resumos, os temas centrais das publicações, embora as teorias e as disciplinas utilizadas para compreender o yoga na Educação Física demonstraram um padrão.

O que entendemos foi a existência de uma grande heterogeneidade disciplinar e teórica. Isto é, os artigos estudados versam sobre os mais variados temas e disciplinas, porém percebemos que dentro desta heterogeneidade temática e disciplinar existe um padrão conceitual que se repete de maneira exponencial que é o de situar o yoga no campo da atividade física que produz benefícios à saúde física e mental, ficando evidente que o interesse maior se volta para o yoga e a saúde corporal em sentido biológico. Nota-se a existência de uma transversalidade do tema yoga para a saúde perpassando os pontos de vista heterogêneos.

Em menor número, mas com recorrência significativa, o tema do yoga articulado com questões sobre cultura corporal também apresenta relevância na preocupação dos pesquisadores. E em menor número estão os artigos que tratam do tema como sendo uma escola filosófica e sistema de disciplinas para a auto realização. Outro aspecto bastante interessante que pudemos observar foi grande parte dos artigos que se situam na área das ciências humanas, ao citar o yoga, o fazem atribuindo a esta prática o sentido de atividade física que trás melhoria da saúde física e mental. Isso significa que as ciências humanas que abordam o yoga a partir de uma perspectiva dualista entre corpo e mente; já que, em termos lógicos, o yoga, por ser uma prática corporal - atividade física -, é destinado aos cuidados do corpo fisiológico e neuronal, enquanto outras práticas culturais, como as artes, por exemplo, abarcariam os cuidados com a dimensão social, intelectual e espiritual da humanidade.

De Rose (2007) descreve os Upanishads como uma grande "virada" filosófica da relação dos hindus consigo mesmos, com o mundo natural e com o universo sobrenatural, a partir da qual os deuses ou as divindades não estariam mais apenas do lado de fora do ser humano, como colocado em textos mais antigos, mas dentro de cada ser (humanos ou não), em seu coração. Além de fazer de todas as coisas naturais o seu lugar, conclui-se que as divindades, formas do Ser (Uno), habitavam o interior do próprio ser humano. Diante dessa suposição a lógica passa a operar de outro modo a ponto de alterar ritos e costumes: se Deus habita em mim e em todos os seres humano, não mais fazia sentido sacrificar animais, plantas, pessoas para oferecer e satisfazer algum ente divino externo. 
De externo, o culto passa a ser interno; cultua-se o mundo interno; o Deus interior. Os Upanishads chamam o aspecto divino de Brahma e o identificam à própria consciência que observa o mundo a partir de dentro de cada um de nós. Tal mudança de perspectiva subjetiva foi o primeiro passo efetivo para a formulação do yoga como disciplina e cuidados formais levada para dentro do corpo; alterando atividades, exercícios e tarefas corporais no hinduísmo mais no sentido de uma hipocinética, do que em direção ao desfrute do vigor físico. Inicialmente é apenas o conceito de yoga que foi sendo delineado; essencialmente o yoga místico que vai sendo delineado neste primeiro momento.

Posteriormente o yoga passa de uma tradição mística - cuja principal característica é o culto de divindades externas ao corpo - a um sistema de filosofia. Que como qualquer filosofia, a tônica litúrgica implica o pensamento interno; a meditação para perceber, escutar, compreender e conhecer esse Deus externo que também habita o interno. Eis resumidamente a epistemologia que guia toda a prática do yoga.

No que tange ainda na classe categorial teórica, a categoria meta do yoga, que foi preenchida após uma leitura mais detalhada dos textos, a maior parte destes citaram o yoga apenas como atividade física voltada para o alcance de uma saúde corporal ao nível fisiológico envolvendo as capacidades como força, flexibilidade, equilíbrio, coordenação etc., sem maior aprofundamento teórico sobre a esta. Acerca de outros trabalhos sequer pudemos inferir uma meta ou objetivo para o yoga, pois apenas citavam a existência dessa prática ou ainda a palavra yoga apareceu somente em suas referências bibliográficas, o que indica que de alguma forma a literatura específica do yoga foi utilizada para embasar textos sobre outras temáticas de maneira subentendida e tácita.

Outra meta atribuída ao yoga que aparece em menor número, mas recorrendo significativamente, é a de atividade física que proporciona alívio do quadro de ansiedade e estresse e produz benefícios mentais e emocionais (não cognitivos ou intelectuais), ou ainda como atividade física que melhora a capacidade motora, flexibilidade bem como a funcionalidade articular. Um número reduzido das publicações situa o yoga no campo das práticas corporais alternativas, que traz ao ser consciência corporal, equilíbrio energético, desenvolve a percepção do ser no mundo, a sensibilidade, criatividade e autoconhecimento, porém sem um grande aprofundamento teórico sobre o por que e como a prática do yoga produziria tais benefícios.

Mais reduzidas ainda foram as publicações que situaram o yoga como sendo uma filosofia, um modo de vida que não se reduz à prática de exercícios, mas que se estende a 
todas as instâncias do dia a dia, como um sistema de disciplinas que tem como meta a auto realização. Hariharananda (2006) explica que com a prática regular do yoga "[...] a pessoa será capaz de controlar os pulmões e o coração, e assim afastar da mente o mundo exterior [inclusive o próprio corpo] [...]" e com isso minimizar ou até neutralizar os efeitos da dor, do sofrimento e de toda carga que está atrelada à prática, promovendo boa saúde. A incorporação de tais preceitos proporcionará paz, equilíbrio mental e desapego; aspectos de suma importância para que se possa alcançar a liberação. Devemos notar que a filosofia do yoga, que orienta uma série de práticas físicas mediante estudos de técnicas corporais, aponta para um paradoxo na visão ocidental da relação entre exercícios corporais e saúde.

O yoga, mais especificamente os ásanas, não passa de uma propedêutica trabalhosa voltada para a promoção do desapego da mente em relação ao corpo através do próprio corpo físico; enquanto que as práticas e técnicas corporais ocidentais orientam a mente para um vínculo e uma preocupação - apego - cada vez maior com a saúde e a estética físico-corporal em si mesmas. No máximo, em termos metafísicos, as práticas de educação do corpo ocidentais buscaram orientar objetivos superiores de cunho moral de base política e econômica. Isso podemos observar nos papeis atribuídos à Educação Física e ao Esporte (assim como às Danças, às Lutas, às Ginásticas) na edificação política tanto do militarismo (comunista ou capitalista) quanto da democracia (socialista ou liberal). Em certo sentido, a metafísica ocidental não deixa de ser profana, enquanto as orientais apontam para o divino.

Diante disto percebemos que na produção acadêmica da Educação Física o tema yoga é, em grande parte, colocado como uma atividade física sem um maior embasamento teórico na literatura clássica ou específica, retirando-o do seu contexto original, e desprovendo de sua essência, pouco se produziu levando em consideração a identidade histórica e epistemológica do yoga. Nós perguntamos se este fato não está atrelado ao interesse de colocar o yoga sob o domínio exclusivo da Educação Física enquanto disciplina paramédica (sob os auspícios do conhecimento médico), pois retirando toda a filosofia e preceitos inerentes ao yoga, que foram desenvolvidos a milênios, o que restaria seria essa atividade física, com séries de alongamentos que cabe aos conteúdos da Educação física limitada à promoção da saúde biológica.

\section{Considerações finais}

Retomando o objetivo deste trabalho, investigar o panorama da produção do conhecimento a partir de periódicos da Educação Física, na tentativa de compreender e 
identificar o tipo de relação a mesma vem estabelecendo com o yoga, percebemos a existência de um choque epistemológico das áreas e no que concerne a compreensão de corpo. O yoga propõe em sua essência a ausência de movimento; em toda a sua prática o movimento corporal existe para dar ao ser a capacidade do não movimento, à abstração dos sentidos e levar a uma internalização para a percepção, do que a literatura clássica denomina de Self. O corpo físico e o movimento existem apenas para que seja possível ao homem atingir tal percepção e finalmente se retirar da vida e se libertar dos ciclos de renascimento e morte. Para a Educação Física a busca é pelo movimento, pela capacidade de movimentar-se, seus objetivos são voltados para a saúde física e mental e para a eficiência do corpo e do movimento.

Para o yoga libertar-se do sofrimento e da lei do Karma seria o objetivo do homem na terra. Cultuar outra dimensão da realidade - ou a realidade mesma, que não se limite ao corpo - para romper com a miséria da vida, com a ignorância da verdadeira natureza do espírito e, nesse sentido, a prática do yoga é o caminho e o meio para alcançar tal objetivo. Karma ou Karmam é a lei da causalidade universal que solidariza o homem com o Cosmos e o condena a transmigrar indefinidamente entre as esferas e modos - estados - de existência físicoespiritual.

Diante deste quadro observamos que não há uma integração entre as áreas sem que uma ou outra perca características e objetivos que lhes são próprios. No caso da atual relação, o yoga está perdendo toda a sua essência quando visto e tratado pela Educação Física apenas como um conteúdo desta área, ligado a atividade física e a eficiência motora, uma vez que todo benefício produzido no corpo pelo yoga é apenas um meio não o fim desta prática. No percurso para se tornar conteúdo da educação Física o yoga vem se manifestando como uma prática rasa, desprovida de seus sentidos originais. A Educação Física quase que reduz o yoga a exercícios de alongamentos e respiratórios. Os textos clássicos desta arte milenar são em grande parte ignorados e toda sua metafísica desenvolvida por séculos posta de lado.

Como forma de promover uma mudança desta relação propomos que os pesquisadores e profissionais do campo da Educação Física aprofundem o conhecimento sobre o yoga, que busquem em outras áreas como na filosofia, nas ciências das religiões, nos clássicos do yoga, para que seja possível uma melhor compreensão e uma não deturpação desta antiga filosofia oriental. A partir de uma nova compreensão de "ser" e de "corpo" por parte da Educação Física acreditamos que a prática do yoga possa contribuir de maneira mais positiva para este campo sem que para isso tenha que perder seus sentidos originais. 


\section{Referencias}

BÁRTOLO, J. Corpo e sentido: estudos intersemióticos. Civilhã: Portugal. Livros LabCom, 2007.

BRACHT, V. Educação física e ciência: cenas de um casamento (in)feliz. IJuí: Unijuí, 1999.

CAPARROZ, F. E.; BRACHT, V. O tempo e o lugar de uma didática da educação física.

Revista Brasileira de Ciências do Esporte, v. 28, n. 2, p. 21-37, jan. 2007.

DE ROSE, A. (Org.). Livro de ouro do yoga. Rio de Janeiro: Ediouro, 2007.

ELIADE, Mircea. Imagens e símbolos. Lisboa: Editora Minerva, 1952.

ELIADE, Mircea. Mito e realidade. São Paulo: Editora Perspectiva, 1972.

ELIADE, Mircea. Yoga: Imortalidade e liberdade. Tradução Teresa de Barros Velloso, Transliteração sânscrita Lia Diskin. São Paulo: Editora Pallas Athena,1996.

GAMBOA, S. Teoria e prática: uma relação dinâmica e contraditória. Motrivivência, Florianópolis, n. 8, p. 31-45, 1995.

HARIHARANANDA, P. Kriya yoga: o processo científico de aperfeiçoamento espiritual e a essência de todas as religiões. Rio de Janeiro: Editora Lótus do Saber, 2006.

HERMÓGENES, José. Autoperfeição com Hatha Yoga. Rio de Janeiro: Record, 1993.

HOURDAKIS, A. Aristóteles e a educação. Tradução de Luiz Paulo Rouanet. São Paulo: Loyola, 2001.

KANT, E. Sobre a pedagogia. São Paulo: UNESP, 2001.

LOCKE, John. Segundo tratado sobre o governo civil: ensaio sobre a origem, os limites e os fins verdadeiros do governo civil. Introdução de J. W. Gough, tradução de Magda Lopes e Marisa Lobo Costa. Petrópolis, RJ: Vozes, 1994.

LOVISOLO, Hugo. Da educação física escolar: intelecto, emoção e corpo. In: Motriz, vol.8 n.3, pp. 99-103, set.-dez 2002.

MOROZ, Melania; GIANFALDONI, Mônica Helena T. A. O processo de pesquisa: iniciação. Brasília: Liber Livro, 2006.

SALMONI, A. Em busca das linguagens perdidas. São Paulo: Editora Perspectiva, 1978.

TINOCO, Carlos Alberto. As Upanishads do yoga. São Paulo: Madras, 2005.

VIVEKANANDA, Swami. O caminho do amor. Tradução Editora Vedanta. São Paulo: Vedanta, 2013. 
VIVEKANANDA, Swami. O que é religião. Tradução Adelaide Petters Lessa. Rio De Janeiro: Lótus, 2004.

YOGANANDA, Paramahansa. A yoga do Bhagavad Gita. Los Angeles, Califórnia: Editora Self- Realization Fellowship, 2009.

YOGANANDA, Paramahansa. A eterna busca do homem. Los Angeles, Califórnia: Editora Self- Realization Fellowship, 2012.

Ana Paula Góis Jatobá

Universidade Federal de Sergipe - Brasil

Professora de Yoga e Pilates da Studio Wave - Aracaju/SE

Licenciada em Educação Física

Membro do grupo de pesquisa "Corpo e Política"

E-mail: paulinha_jatoba@ hotmail.com

Dr.Renato Izidoro da Silva

Universidade Federal de Sergipe - Brasil

Professor do Departamento de Educação Física

Professor do programa de Pós-graduação em Educação (PPGED) e do programa de pósgraduação em cinema (PPGCINE) da UFS. Doutor em Educação pela Universidade Federal da Bahia - UFBA. Coordenador do grupo "Corpo e Política" da UFS. E-mail. izidoro.renato@gmail.com

Dr. Fabio Zoboli

Universidade Federal de Sergipe - Brasil

Professor do Departamento de Educação Física

Programa de Pós-graduação em Educação Programa de Pós-Graduação em Cinema. Pós Doutorando em "Educação do corpo" pela Facultad de humanidades e ciencias de la educación da Universidad Nacional de La Plata - Argentina. Doutor em Educação pela Universidade Federal da Bahia - UFBA. Membro do grupo "Corpo e Política" da UFS. E-mail.zobolito@gmail.com

Recebido em 09 de novembro de 2016 Aprovado em 07 de dezembro de 2016 